\title{
Neurointervention in the 2020s: Where are We Going?
}

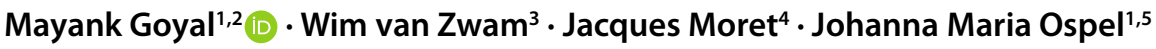

Received: 23 June 2020 / Accepted: 8 August 2020 / Published online: 11 September 2020

(c) Springer-Verlag GmbH Germany, part of Springer Nature 2020

\section{A Brief Summary of the History of Neurointervention}

\section{The 1970s and 1980s-Discovery}

The history of neurointervention is short as our field is still in its puberty. If one had to pinpoint a starting date, most would agree it was the early 1970s, although Luessenhop and Spence described a case of an endovascular embolization of a brain arteriovenous malformation as early as 1960 [1]. The 1970s was the time when the pioneers of the field boldly went where no one had gone before. Their brilliant minds made huge advancements in the understanding of complex vessel anatomy and neurovascular pathology, and we have to particularly recognize the tremendous input of Pierre Lasjaunias in the delicate and precise description of the vascular microanatomy of the base of the skull, and Fedor Serbinenko, who developed a technique to treat intracranial aneurysms and carotid cavernous sinus fistulas with a detachable latex balloon [2]. In the 1980s, Zeumer and Theron entered the field of endovascular stroke treatment and opened intracranial occlusions with locally administered fibrinolytics [3, 4]. Only a few conditions were treatable but the sudden knowledge gain was massive and

\section{Mayank Goyal}

mgoyal@ucalgary.ca

1 Department of Clinical Neurosciences, University of Calgary, Calgary, Canada

2 Department of Radiology, University of Calgary, Calgary, Canada

3 Department of Radiology and Nuclear Medicine, Cardiovascular Research Institute Maastricht, School for Mental Health and Sciences, Maastricht University Medical Center, Maastricht, The Netherlands

4 The Brain Vascular Center, Baujon University Hospital, Paris, France

5 Division of Neuroradiology, Clinic of Radiology and Nuclear Medicine, University Hospital Basel, University of Basel, Basel, Switzerland led to an aura of intrigue and excitement that attracted numerous talented young clinician researchers to the field. This led to the foundation of the first companies that were dedicated to manufacturing devices for endovascular minimally invasive procedures.

\section{The 1990s-Innovation}

In the early 1990 s one of the most groundbreaking inventions in our specialty was made: the Guglielmi detachable coil was used for the first time in a patient with a carotid artery aneurysm in 1990 [5] and by the end of the 1990s endovascular coiling became a well-established treatment option for both ruptured and unruptured aneurysms [6]. Procedural innovation paralleled engineering innovations, and leaders in the field started treating seemingly impossible aneurysms with various neck-bridging techniques [7]. Neurointerventionalists at that time also experimented with existing technologies in other conditions, such as brain arteriovenous malformations (AVM), carotid stenosis and acute stroke, but were unable to make massive inroads. It was in the 1990s when Pierre Lasjaunias and Alex Berenstein wrote the first version of "Surgical Neuroangiography", which was complemented by several other volumes later on [8]. In summary, the 1990s were an era of charismatic personalities, enthusiasm and innovations, and neurointervention was centered in few high-volume centers around these personalities. However, little emphasis was put on evidence-based medicine. Research in neurointervention in this decade mainly consisted of book-keeping of one's patients, i.e. counting patients and reporting outcomes in a purely descriptive and often unsystematic fashion.

\section{The 2000s-Early Steps Towards Evidence-based Medicine}

This changed in the 2000s, when the first major randomized trial in our field was conducted and published: the International Subarachnoid Aneurysm Trial (ISAT) compared clinical outcomes of endovascular coiling vs. surgi- 
cal clipping for ruptured intracranial aneurysms and showed a clear benefit in the coiling arm [9]. As a result, aneurysm coiling became mainstream and so did neurointervention. Large academic hospitals around the world quickly converted from open surgery to minimally invasive aneurysm treatment. As expected, this triggered a new wave of innovation. Driven by the increasing demand, advanced techniques, such as balloon-assisted coiling, stent-assisted coiling and flow diversion were developed [10], and numerous new coils of varying shapes and degrees of stiffness were designed, which in turn, resulted in further increases in endovascular aneurysm treatment. On the other hand, early trials on carotid stenting, such as the SPACE trial, had disappointing results, possible due to several methodological flaws, including poor operator selection and credentialing mechanisms [11]. It was in the early 2000s when dedicated intracranial stents and Onyx became available and substantially improved treatment of intracranial stenosis and brain AVMs [12]. The 2000s were also the decade in which the phenomenon of the multidimensional physician, who is inventor and entrepreneur simultaneously, occurred for the first time, although the general public viewed and continues to view physicians with entrepreneurial goals somewhat skeptically.

\section{The 2010s-Explosion of the Field}

In the second decade of the century, the field suddenly exploded. While earlier attempts of trials aiming to demonstrate the benefit of endovascular treatment for patients with acute ischemic stroke, such as PROACT II [13] and IMS III [14] were unsuccessful, five major randomized controlled trials finally showed an overwhelming benefit of mechanical thrombectomy compared to medical management alone for acute ischemic stroke due to large vessel occlusion [15]. Since the treatment became standard of care in 2015, and again driven by the existing demand for better treatment devices, the second half of the decade was characterized by a remarkable growth in technique and technology (who would have thought 10 years earlier in 2005 that we would routinely take a 6 French catheter into the middle cerebral artery?). Inspired by the results of the first trials, industry and funding agencies provided the necessary resources for additional randomized trials, such as DAWN [16] and DEFUSE 3 [17], which were well-designed and meticulously executed by dedicated leaders in the field. The results were again overwhelmingly positive and led to further loosening of eligibility criteria for mechanical thrombectomy. At the same time, innovations in aneurysm treatment continued with the development of endosaccular flow disruption $[18,19]$, which made treatment of wide-necked bifurcation aneurysms much easier. In the 2010s our field also experienced exponential growth in the number of neu- roendovascular centers and training programs, and the total number of operators rose to accommodate the manpower needed to tackle the growing demands, particularly in acute stroke treatment. As an expected side effect, the number of aneurysms and arteriovenous malformations treated per operator dropped. While the 2010s marked a revolution in acute ischemic stroke treatment, they were also a decade of disappointment with respect to intracranial stenting and endovascular brain AVM treatment, with the SAMMPRIS and ARUBA trials showing no benefit of endovascular treatment for these conditions [20, 21]. For acute ischemic stroke the breakthrough was made but as far as brain AVMs and carotid stenting was concerned, the neurointerventional community was forced to return to the drawing board and rethink their approach to these diseases.

\section{The Future-Where are We Going?}

What will the 2020s bring, what should we collectively aim for and what should we try to avoid?

\section{Undesirable Developments that Will Likely Happen in the near Future (but can be Avoided)}

An honest assessment of the future of neurointervention should also include undesirable developments that are likely to happen, the most important of which is dilution of expertise and experience. Since mechanical thrombectomy has become standard of care, there has been and continues to be an exponential increase in hospitals offering neurovascular services, with a subsequent decrease in operator and institutional caseload. In other words: we will face dilution of experience. Centers in which a neurointerventional stroke service has been established will probably start to offer treatment for other conditions, such as intracranial aneurysms and arteriovenous malformations as well, even if they might not have the necessary volume to maintain a high level of expertise. This may decrease overall treatment quality. It could also lead to unnecessary or unwarranted procedures to maintain volume, experience and certification criteria. Additional burden of call and the increased interest in the field may cause young trainees to struggle and prevent them from having a fulfilling career after their training [22]. Economic pressure, commercial interests of healthcare providers, misaligned financial incentives and privatization of hospitals impose additional serious threats on patient care and further complicate the situation. Preventing these undesirable events would require rigorous quality standards and minimum caseload requirements as well as consistent and objective monitoring of patient outcomes, all of which will be highly challenging to establish. Of course, we very much hope that we are wrong! We are firm believ- 
ers that performing neurointerventional procedures should require a high standard of expertise and training, and that we should make it our highest priority to avoid dilution of these standards.

\section{Desirable Developments that Will Likely Happen in the Near Future}

On the other hand, there are many desirable developments that are already on the horizon: for example, it is highly likely that mechanical thrombectomy for acute stroke will further expand as several randomized controlled trials that investigate patients at the fringes of current treatment guidelines are already underway [23, 24]. This will most likely be accompanied by advancements in treatment technology that will allow us to achieve even faster and better reperfusion results. We might also experience a shift of imaging from the in-hospital to the prehospital phase. Several prehospital imaging tools are currently in development that could allow us to identify and triage large vessel occlusions prior to hospital arrival [25]. Machine learning tools could soon help to democratize stroke imaging through automatization and standardization of image acquisition and interpretation [26]. Device surfaces will also likely experience significant advancements. Surfaces of current stents and flow diverters are highly thrombogenic and thus require dual antiplatelet medication. There is however an ongoing race among manufacturers to develop antithrombogenic coatings for stents and flow diverters to obviate the need for dual antiplatelet regimens. First case series have already been published and show encouraging results [27, 28]. Remote mentoring is another highly desirable development that will probably soon find its way into clinical routine, partly because one-onone/in person teaching has become very challenging, if not impossible, during the COVID-19 pandemic. This has led to a dramatic increase in demand for online teaching resources, virtual discussion forums and remote mentoring [29]. Recent studies have already shown the feasibility and safety of remote live streaming support for emergency neurointerventional procedures, such as mechanical thrombectomy [30]. Fueled by the current travel restrictions, it is likely that these novel mentoring approaches will be used more and more, particularly in more rural areas.

\section{Desirable Developments We Should Aim for in the Near Future}

Other developments that would be desirable will probably require more groundwork, but they might still become reality in the medium term. One example is a reduction in variance of operator performance through simulation technology. Current simulators still lack adequate haptic feedback, are restricted to a relatively narrow repertoire of de- vices, and individual patient anatomy cannot be routinely simulated. Changing this will take time as it requires substantial advancements in existing technology; however, with several companies around the globe working on these problems, we have reason to hope that within the next decade, sophisticated simulators will equalize differences in training, thereby "squeezing the bell curve" of human performance and reducing negative outliers. Closely related to this topic is the introduction of robotics into the neurointerventional routine. To date, few groups have reported small case series of successful robot-assisted elective procedures [31-33], and first attempts are being made to create ethical and medicolegal frameworks [34] for neurointerventional robotics. The degree of autonomy of current robotic systems is however very low and their utility restricted by the incapability of performing essential tasks, such as puncturing the groin. Limited stability of network infrastructures and imaging transfer protocols have to be overcome in order to tap the full potential of robotics, and as always, cost may be a major stumbling block. It is not only changes in technology but also in our own thinking that move our field forward. One example is multifactorial decision making in endovascular stroke treatment. Current treatment guidelines are rather rigid and consist of a list of eligibility criteria; as soon as one of these criteria is not met, a patient is considered ineligible for endovascular stroke treatment. This however does not adequately address the complex interplay of individual patient characteristics and local infrastructural circumstances. To date, there is no comprehensive decision tool yet that takes all these factors into account, but several research teams are working on solving this problem [35]. Whether such tools get accepted by guideline committees and can be integrated in clinical routine remains to be seen.

\section{Desirable Developments that Will not Happen in the Near Future}

Lastly, there are the future dreams - things that might eventually become reality in the distant future but for the time being it is unforeseeable whether and when this will be the case. Many of these do not fall under the category of technological advancements but are more related to human behavior. For example, we still lack good randomized controlled trial data for the treatment of unruptured brain aneurysms, and this is unlikely to change within the current decade. The same is true for the ability to practice evidence-based medicine in the treatment of unruptured brain arteriovenous malformations [36]. Furthermore, as new diagnostic tools and treatment technologies are emerging at a rapid pace and sometimes find their way into clinical routine based on anecdotal evidence, our field would largely benefit from a systematic approach to adopting new technologies. A systematic and comprehensive recording of treatment success 
rates and complications beyond what is necessary and mandated by approval agencies would enable a genuine comparison to existing tools and techniques and to the natural history of the disease, thereby preventing dangerous and harmful practice. This is however unlikely to happen mainly because 1) there are no good mechanisms to ensure that all patients get enrolled in such a database and 2) there is little willingness on the part of device manufacturers/ hospitals/regulatory bodies/governments/insurers to pay for such databases.

Neither the summary of past achievements in our field nor the outlook on potential future directions as described above are intended as a comprehensive summary. It is merely our intention to point out some interesting aspects of the future and the past. We fully acknowledge that the viewpoint presented is a personal and subjective one; we hope that it will nevertheless lead to productive discussions and debates. In particular, we hope to initiate a thought process on how we as a professional community can work towards avoiding undesirable events that are about to happen, such as a dilution of experience and skills, and how we can facilitate desirable but unlikely developments, such as a stronger emphasis on evidence-based medicine: in this respect, we would love to be wrong as the future unfolds.

Acknowledgements The authors would like to thank Prof. Jens Fiehler for his input.

Author Contribution Mayank Goyal: conceptualization, drafting and critical revision of the manuscript. Johanna Ospel: drafting and critical revision of the manuscript and figures. Remaining authors: critical revision of the manuscript.

Conflict of interest M. Goyal is a consultant for Medtronic, Stryker, Microvention, Mentice, GE Healthcare, and holds a licensing agreement with GE Healthcare regarding systems of acute stroke diagnosis. W. van Zwam, J. Moret and J.M. Ospel declare that they have no competing interests.

\section{References}

1. Luessenhop AJ, Spence WT. Artificial embolization of cerebral arteries. Report of use in a case of arteriovenous malformation. J Am Med Assoc. 1960;172:1153-5.

2. Serbinenko FA. Balloon catheterization and occlusion of major cerebral vessels. J Neurosurg. 1974;41:125-45.

3. Zeumer H, Hacke W, Kolmann HL, Poeck K. Lokale Fibrinolysetherapie bei Basilaris-Thrombose. Dtsch Med Wochenschr. 1982;107:728-31.

4. Theron J, Courtheoux P, Casasco A, Alachkar F, Notari F, Ganem F, Maiza D. Local intraarterial fibrinolysis in the carotid territory. AJNR Am J Neuroradiol. 1989;10:753-65.

5. Guglielmi G. History of endovascular endosaccular occlusion of brain aneurysms: 1965-1990. Interv Neuroradiol. 2007;13:217-24.

6. Pierot L, Wakhloo AK. Endovascular treatment of intracranial aneurysms: current status. Stroke. 2013;44:2046-54.

7. Moret J, Cognard C, Weill A, Castaings L, Rey A. The "Remodelling Technique" in the Treatment of Wide Neck Intracranial
Aneurysms. Angiographic Results and Clinical Follow-up in 56 Cases. Interv Neuroradiol. 1997;3:21-35.

8. Lasjaunias P, Berenstein A. Surgical neuroangiography. Berlin, Heidelberg, New York: Springer; 1994.

9. Molyneux AJ, Kerr RS, Yu LM, Clarke M, Sneade M, Yarnold JA, Sandercock P; International Subarachnoid Aneurysm Trial (ISAT) Collaborative Group. International subarachnoid aneurysm trial (ISAT) of neurosurgical clipping versus endovascular coiling in 2143 patients with ruptured intracranial aneurysms: a randomised comparison of effects on survival, dependency, seizures, rebleeding, subgroups, and aneurysm occlusion. Lancet. 2005;366:809-17.

10. Fiorella D, Woo HH, Albuquerque FC, Nelson PK. Definitive reconstruction of circumferential, fusiform intracranial aneurysms with the pipeline embolization device. Neurosurgery. 2008;62: 1115-20; discussion 1120-1.

11. Eckstein HH, Ringleb P, Allenberg JR, Berger J, Fraedrich G, Hacke W, Hennerici M, Stingele R, Fiehler J, Zeumer H, Jansen O. Results of the Stent-Protected Angioplasty versus Carotid Endarterectomy (SPACE) study to treat symptomatic stenoses at 2 years: a multinational, prospective, randomised trial. Lancet Neurol. 2008;7:893-902.

12. Jahan R, Murayama Y, Gobin YP, Duckwiler GR, Vinters HV, Viñuela F. Embolization of arteriovenous malformations with Onyx: clinicopathological experience in 23 patients. Neurosurgery. 2001;48:984-95; discussion 995-7.

13. Furlan A, Higashida R, Wechsler L, Gent M, Rowley H, Kase C, Pessin M, Ahuja A, Callahan F, Clark WM, Silver F, Rivera F. Intra-arterial prourokinase for acute ischemic stroke. The PROACT II study: a randomized controlled trial. Prolyse in Acute Cerebral Thromboembolism. JAMA. 1999;282:2003-11.

14. Broderick JP, Palesch YY, Demchuk AM, Yeatts SD, Khatri P, Hill MD, Jauch EC, Jovin TG, Yan B, Silver FL, von Kummer R, Molina CA, Demaerschalk BM, Budzik R, Clark WM, Zaidat OO, Malisch TW, Goyal M, Schonewille WJ, Mazighi M, Engelter ST, Anderson C, Spilker J, Carrozzella J, Ryckborst KJ, Janis LS, Martin RH, Foster LD, Tomsick TA; Interventional Management of Stroke (IMS) III Investigators. Endovascular therapy after intravenous t-PA versus t-PA alone for stroke. N Engl J Med. 2013;368:893-903. Erratum in: N Engl J Med. 2013;368:1265.

15. Goyal M, Menon BK, van Zwam WH, Dippel DW, Mitchell PJ, Demchuk AM, Dávalos A, Majoie CB, van der Lugt A, de Miquel MA, Donnan GA, Roos YB, Bonafe A, Jahan R, Diener HC, van den Berg LA, Levy EI, Berkhemer OA, Pereira VM, Rempel J, Millán M, Davis SM, Roy D, Thornton J, Román LS, Ribó M, Beumer D, Stouch B, Brown S, Campbell BC, van Oostenbrugge RJ, Saver JL, Hill MD, Jovin TG; HERMES collaborators. Endovascular thrombectomy after large-vessel ischaemic stroke: a meta-analysis of individual patient data from five randomised trials. Lancet. 2016;387:1723-31.

16. Nogueira RG, Jadhav AP, Haussen DC, Bonafe A, Budzik RF, Bhuva P, Yavagal DR, Ribo M, Cognard C, Hanel RA, Sila CA, Hassan AE, Millan M, Levy EI, Mitchell P, Chen M, English JD, Shah QA, Silver FL, Pereira VM, Mehta BP, Baxter BW, Abraham MG, Cardona P, Veznedaroglu E, Hellinger FR, Feng L, Kirmani JF, Lopes DK, Jankowitz BT, Frankel MR, Costalat V, Vora NA, Yoo AJ, Malik AM, Furlan AJ, Rubiera M, Aghaebrahim A, Olivot JM, Tekle WG, Shields R, Graves T, Lewis RJ, Smith WS, Liebeskind DS, Saver JL, Jovin TG; DAWN Trial Investigators. Thrombectomy 6 to 24 Hours after Stroke with a Mismatch between Deficit and Infarct. N Engl J Med. 2018;378:11-21.

17. Albers GW, Marks MP, Kemp S, Christensen S, Tsai JP, OrtegaGutierrez S, McTaggart RA, Torbey MT, Kim-Tenser M, LeslieMazwi T, Sarraj A, Kasner SE, Ansari SA, Yeatts SD, Hamilton S, Mlynash M, Heit JJ, Zaharchuk G, Kim S, Carrozzella J, Palesch YY, Demchuk AM, Bammer R, Lavori PW, Broderick JP, Lansberg MG; DEFUSE 3 Investigators. Thrombectomy for Stroke at 6 
to 16 Hours with Selection by Perfusion Imaging. N Engl J Med. 2018;378:708-18.

18. Pierot L, Costalat V, Moret J, Szikora I, Klisch J, Herbreteau D, Holtmannspötter M, Weber W, Januel AC, Liebig T, Sychra V, Strasilla C, Cognard C, Bonafé A, Molyneux A, Byrne JV, Spelle L. Safety and efficacy of aneurysm treatment with WEB: results of the WEBCAST study. J Neurosurg. 2016;124:1250-6.

19. Pierot L, Gubucz I, Buhk JH, Holtmannspötter M, Herbreteau D, Stockx L, Spelle L, Berkefeld J, Januel AC, Molyneux A, Byrne JV, Fiehler J, Szikora I, Barreau X. Safety and Efficacy of Aneurysm Treatment with the WEB: Results of the WEBCAST 2 Study. AJNR Am J Neuroradiol. 2017;38:1151-5.

20. Chimowitz MI, Lynn MJ, Derdeyn CP, Turan TN, Fiorella D, Lane BF, Janis LS, Lutsep HL, Barnwell SL, Waters MF, Hoh BL, Hourihane JM, Levy EI, Alexandrov AV, Harrigan MR, Chiu D, Klucznik RP, Clark JM, McDougall CG, Johnson MD, Pride GL Jr, Torbey MT, Zaidat OO, Rumboldt Z, Cloft HJ; SAMMPRIS Trial Investigators. Stenting versus aggressive medical therapy for intracranial arterial stenosis. N Engl J Med. 2011;365:993-1003. Erratum in: N Engl J Med. 2012;367:93.

21. Mohr JP, Parides MK, Stapf C, Moquete E, Moy CS, Overbey JR, Al-Shahi Salman R, Vicaut E, Young WL, Houdart E, Cordonnier C, Stefani MA, Hartmann A, von Kummer R, Biondi A, Berkefeld J, Klijn CJ, Harkness K, Libman R, Barreau X, Moskowitz AJ; international ARUBA investigators. Medical management with or without interventional therapy for unruptured brain arteriovenous malformations (ARUBA): a multicentre, non-blinded, randomised trial. Lancet. 2014;383:614-21.

22. Fargen KM, Arthur AS, Leslie-Mazwi T, Garner RM, Aschenbrenner CA, Wolfe SQ, Ansari SA, Dabus G, Spiotta A, Mokin M, Linfante I, Mocco J, Hirsch JA. A survey of burnout and professional satisfaction among United States neurointerventionalists. J Neurointerv Surg. 2019;11:1100-4.

23. Bendszus M, Bonekamp S, Berge E, Boutitie F, Brouwer P, Gizewski E, Krajina A, Pierot L, Randall G, Simonsen CZ, Zeleňák $\mathrm{K}$, Fiehler J, Thomalla $\mathrm{G}$. A randomized controlled trial to test efficacy and safety of thrombectomy in stroke with extended lesion and extended time window. Int J Stroke. 2019;14:87-93.

24. In Extremis. 2020. https://www.inextremis-study.com. Accessed 26 Mar 2020.

25. Forest Devices. 2020. https://www.forestdevices.com. Accessed 26 Mar 2020.

26. Qiu W, Kuang H, Teleg E, Ospel JM, Sohn SI, Almekhlafi M, Goyal M, Hill MD, Demchuk AM, Menon BK. Machine Learning for Detecting Early Infarction in Acute Stroke with Non-Contrast-enhanced CT. Radiology. 2020;294:638-44.

27. Aguilar Perez M, AlMatter M, Hellstern V, Wendl C, Ganslandt $\mathrm{O}$, Bäzner H, Henkes H. Use of the pCONus HPC as an adjunct to coil occlusion of acutely ruptured aneurysms: early clinical experience using single antiplatelet therapy. J Neurointerv Surg. 2020;12:862-8.
28. Manning NW, Cheung A, Phillips TJ, Wenderoth JD. Pipeline shield with single antiplatelet therapy in aneurysmal subarachnoid haemorrhage: multicentre experience. J Neurointerv Surg. 2019;11:694-8.

29. Fiehler J, Brouwer P, Díaz C, Hirsch JA, Kulcsar Z, Liebeskind D, Linfante I, Lylyk P, Mack WJ, Milburn J, Nogueira R, Orbach DB, Pumar JMM, Tanaka M, Taylor A. COVID-19 and neurointerventional service worldwide: a survey of the European Society of Minimally Invasive Neurological Therapy (ESMINT), the Society of NeuroInterventional Surgery (SNIS), the Sociedad Iberolatinoamericana de Neuroradiologia Diagnostica y Terapeutica (SILAN), the Society of Vascular and Interventional Neurology (SVIN), and the World Federation of Interventional and Therapeutic Neuroradiology (WFITN). J Neurointerv Surg. 2020;12:726-30.

30. Bechstein M, Buhk JH, Frölich AM, Broocks G, Hanning U, Erler M, Anđelković M, Debeljak D, Fiehler J, Goebell E. Training and Supervision of Thrombectomy by Remote Live Streaming Support (RESS) : Randomized Comparison Using Simulated Stroke Interventions. Clin Neuroradiol. 2019 Dec 20. https://doi.org/10.1007/ s00062-019-00870-5. Epub ahead of print.

31. Mendes Pereira V, Cancelliere NM, Nicholson P, Radovanovic I, Drake KE, Sungur JM, Krings T, Turk A. First-in-human, robotic-assisted neuroendovascular intervention. J Neurointerv Surg. 2020;12:338-40.

32. Nogueira RG, Sachdeva R, Al-Bayati AR, Mohammaden MH, Frankel MR, Haussen DC. Robotic assisted carotid artery stenting for the treatment of symptomatic carotid disease: technical feasibility and preliminary results. J Neurointerv Surg. 2020;12:341-4.

33. Sajja KC, Sweid A, Al Saiegh F, Chalouhi N, Avery MB, Schmidt RF, Tjoumakaris SI, Gooch MR, Herial N, Abbas R, Zarzour H, Romo V, Rosenwasser R, Jabbour P. Endovascular robotic: feasibility and proof of principle for diagnostic cerebral angiography and carotid artery stenting. J Neurointerv Surg. 2020;12:345-9.

34. Albuquerque FC, Hirsch JA, Chen M, Fiorella D. Robotics in neurointervention: the promise and the reality. J Neurointerv Surg. 2020;12:333-4.

35. Venema E, Mulder MJHL, Roozenbeek B, Broderick JP, Yeatts SD, Khatri P, Berkhemer OA, Emmer BJ, Roos YBWEM, Majoie CBLM, van Oostenbrugge RJ, van Zwam WH, van der Lugt A, Steyerberg EW, Dippel DWJ, Lingsma HF. Selection of patients for intra-arterial treatment for acute ischaemic stroke: development and validation of a clinical decision tool in two randomised trials. BMJ. 2017;357:j1710.

36. Goyal M, Ospel JM, Kashani N, Siddiqui AH, Hanel R, Almekhlafi M, Chapot R. What neurointerventionists think about the treatment of unruptured brain arteriovenous malformations: the complexity of moving towards evidence-based treatment. Neuroradiology. 2020;62:411-6. 